\title{
Quais as tarefas necessárias à educação em tempos de ascensão do conservadorismo?
}

\author{
¿Cuáles son las tareas necesarias para la educación en tiempos de \\ ascenso del conservadurismo?
}

What tasks do education need in times of conservatism?

Julia Rocha Clasen ${ }^{1}$

\begin{abstract}
Resumo
Com a intenção de compreender o atual cenário político e as tarefas interpostas à educação em uma conjuntura de necessária resistência, é proposto neste trabalho, refletir acerca das características que o campo educacional assume em meio à ascensão do conservadorismo e retrocessos sociais em curso. A metodologia proposta nesta reflexão é de cunho qualitativo, referenciada por um levantamento bibliográfico acerca do sistema educacional e relações de resistência frente aos projetos educacionais formulados em face do desenvolvimento capitalista. Compreendendo a educação, enquanto parte de um sistema de produção, que permeia diferentes âmbitos da vida dos sujeitos e, estando assim, comprometida em cumprir determinado projeto de sociedade assume uma forma própria frente a este, de formação de sujeitos com papéis sociais a serem incorporados. Sendo ao mesmo passo o sistema escolar, campo de reprodução de relações de produção, é também meio que educa, o educar aqui compreendido enquanto prática de resistência no sistema de estratificação social. Educa, desta forma, no sentido essencial do termo, para a vida social, formando o indivíduo enquanto ser crítico. É nesse sentido que é pretendido neste trabalho, refletir acerca das tarefas de resistência assumidas pelo campo da educação frente à conjuntura política do país, dimensionando a atuação dos estudantes secundaristas no ano de 2016 enquanto importante momento para refletirmos o repertório de ação para o período que segue.
\end{abstract}

Palavras-Chave: Educação; Conservadorismo; Resistência.

\section{Resumén}

A través de la intención de compreender la atual paisaje política y las tareas interpuestas a la educación en un momiento de indispensable resistencia, es propuesto neste trabajo, reflexionar acerca de las características que el campo educativo asume en medio de la ascensión del conservadurismo y retrocesos sociales en juego. Una propuesta metodológica de reflexión cualitativa, referencia para el levantamiento bibliográfico acerca del sistema educativo y las relaciones de resistencia frente a proyectos educativos formulados en el desarrollo capitalista. Compreendendo la educación enquanto parte del sistema de producción, que se refiere a la vida de los hombres y las mujeres, se les asigna, se compromete a los resultados del proyecto de la sociedad, se asume la forma de la prótesis y la forma más reciente. Sendo al mismo paso lo sistema escolar, es el campo de reprodución de relaciones de producción y también el sitio que educa, el educar aquí comprendido como práctica de resistencia en el sistema de estratificación social. Educa, de esta forma, en el sentido esencial del término, para la vida social, formando al individuo como ser crítico. Este es el sentido de lo que se presenta en este trabajo, se trata de un tema de resistencia que se asume en el campo de la educación en el plano de la política política del país, y se cuenta con una evaluación de los estudios secundaristas hasta el año 2016.

\footnotetext{
1 Mestranda em Educação; Universidade Federal de Pelotas; Pelotas, Rio Grande do Sul, Brasil; clasenjulia1@gmail.com.
} 
Palabras claves: Educación; Conservadorismo; Resistencia

\begin{abstract}
Intending to understand the current political scenario and the tasks involved in education in a context of necessary resistance, it is proposed in this paper to reflect on the characteristics that the educational field assumes amid the rise of conservatism and ongoing social setbacks. The methodology proposed in this reflection is qualitative, referenced by a bibliographical survey about the educational system and resistance relations with educational projects formulated in the face of capitalist development. Understanding education, as part of a production system that permeates different spheres of the subjects lives and, thus, committed to fulfill certain project of society, assumes its own shape towards this project, of training subjects with social roles to be incorporated. The school system being, at the same time, a relations of production field of reproduction, it is also a mean of educating, the education understood here as a practice of resistance in the system of social stratification. It educates, then, in the essential meaning of the term, for social life, forming the individual as a critical being. It is in this sense that this paper intends to reflect on the resistance tasks assumed by the field of education towards the country's political conjuncture, by sizing the performance of the secondary students in the year of 2016 as an important moment to reflect the repertoire of action for the succeeding period.
\end{abstract}

Keywords: Education; Conservatism; Resistance.

\title{
1.Introdução
}

O atual cenário político do país, toma cada vez mais uma face conservadora e antidemocrática, representada por um cotidiano de ataques ao conjunto da classe trabalhadora. Em meio a uma conjuntura de ascensão da ofensiva política neoconservadora, agora não mais apenas esboçada, mas sim aclarada com o panorama eleitoral no ano de 2018, a educação é alvo de retrocessos e ataques, a partir de medidas que direcionam-se no sentido de uma intensificação de um projeto de privatização da educação pública.

É proposto, neste trabalho, travar debates acerca das tarefas colocadas à educação frente ao atual cenário, pontuando a forma social que o sistema educacional assume em uma sociedade de classes. Entendendo enquanto inviável dimensiona-lo sem aprofundar reflexões acerca do sistema de produtivo, o qual dita o projeto educacional em curso.

Nesse sentido, é proposto retomar as ações de resistência do último período, principalmente no campo educacional, dimensionando-as enquanto aporte formador para o atual contexto político, compreendendo a atuação dos estudantes secundaristas no ano de 2016 enquanto relevante momento de mobilização frente aos ataques em curso, que visavam um programa mercantil dos serviços públicos, assumido também como orientador do atual governo.

Sendo este traçado, a partir de um conjunto de ações que visam o aprofundamento da situação de exploração, representado por um discurso conservador que expõe sua ofensiva e intencionalidade de ameaça à direitos sociais, tão duramente conquistados. 
Nesse contexto, a educação já em condições de precarização e sucateamento, é alvo de medidas de privatização que demonstram um agravante aprofundamento para o próximo período. Representando uma intensificação dos retrocessos impostos pelos agentes do capital, esboçados segundo uma lógica assegurada por uma concepção falaciosa de "neutralidade do conhecimento". Sendo concebida pela repressão ao pensamento crítico e imposição de um projeto que fere o processo de ensino e a educação enquanto aspecto inerente à formação humana.

Nesse sentido, pretende-se traçar o que permaneceu da luta dos estudantes no ano de 2016 e de qual modo sua estratégia de atuação é aporte para projeção do repertório de resistência da classe trabalhadora no próximo período.

Buscando aqui estabelecer a dimensão política dos movimentos sociais, entendendo estes em uma perspectiva de transformação estrutural. Segundo Galvão "Os movimentos sociais são, de um lado, expressão das contradições de classes e, de outro, contribuem para a constituição das classes (já que elas se constituem na luta, não estão dadas automaticamente pela posição na estrutura produtiva)" (GALVÃO, 2011, p.123).

Os estudantes secundaristas, durante o ano de 2016, em um movimento nacional de ocupação, pautaram a necessidade de reformulação da educação, resistindo a medidas que representavam um projeto intensificado de privatização e sucateamento da educação pública. A mobilização demonstrando-se para além de um momento pontual de ação coletiva, representou a tarefa assumida pelos estudantes de mobilização da classe trabalhadora frente aos ataques em curso e de formulação acerca de um projeto de educação emancipador.

Propondo neste trabalho traçar o potencial transformador dessa luta ao campo educacional, que adentra um período de amputação ao fazer pedagógico e de perseguição aqueles que tem na educação um processo de formação consciente do indivíduo. A metodologia empregada neste trabalho é de cunho qualitativa, tratando-se de um levantamento bibliográfico sobre a produção acerca da temática levantada, abarcando uma compreensão do sistema educacional em uma sociedade de classes e dos movimentos sociais relativos ao último período.

Aprofundando a observação sobre o ano de 2016, pelo caráter de vanguarda dos estudantes secundaristas nas mobilizações relativas aquele período. As quais foram resultantes de um amplo debate sobre o sistema de ensino e as relações de aprendizagem, atualmente vivenciadas, provendo neste sentido, condições para reflexão acerca das tarefas do campo educacional no atual cenário político. 


\section{Desenvolvimento}

No ano de 2016, os estudantes secundaristas, em um movimento de organização nacional, ocuparam mais de mil escolas em 19 estados brasileiros $^{2}$, tendo como principais pautas os retrocessos em curso, assumido pelo governo Michel Temer (PMDB), esses ataques compreendiam um projeto de intensa privatização e precarização dos setores sociais, com a Proposta de Emenda Constitucional (PEC) 241, que institui o Novo Regime Fiscal, estabelecendo limites para os gastos públicos em educação e saúde por 20 anos e a Medida Provisória (MP) 746/2016, que propõe a Reforma do Ensino Médio ${ }^{3}$, representando assim, um profundo ataque à educação pública.

Esse movimento de ocupação para além de uma estratégia de resistência dos estudantes, frente aos ataques em curso, demonstrou a força política da categoria ao assumir um papel de vanguarda das mobilizações do conjunto da classe trabalhadora, em uma conjuntura de duros ataques e retrocessos sociais.

A mobilização estudantil também propôs uma reflexão acerca do sistema educacional em sua amplitude, sendo exposto o desacordo dos estudantes com as relações de ensino como eram vivenciadas, propondo um formato de ensino que estivesse em profundo diálogo com as lutas sociais e reivindicando ao longo desse processo, um projeto de educação verdadeiramente emancipatório.

Não representando apenas uma ação pontual de resistência, mas uma mobilização que deixaria marcas no espaço escolar, reformulando as relações de ensino. Nesse sentido recorrese ao entendimento deste momento político como aporte para reflexão acerca das tarefas colocadas ao campo educacional na atual conjuntura.

Compreendendo o pacote de medidas assumidos no último período enquanto um ataque ao pensamento crítico e, também as relações de ensino em sua essência, partindo de um entendimento destas para além de um ato mecanicista de aprendizagem. É preciso compreender a educação para além dos processos formais de aprendizagem, abarcando-a enquanto aspecto inerente à formação humana, a qual está presente nos diferentes espaços e momentos da vida do indivíduo.

\footnotetext{
${ }^{2}$ No dia 28 de outubro de 2016 a União Brasileira dos Estudantes Secundaristas (UBES) lança uma lista com as escolas ocupadas, um número que chega a 1197 escolas. Disponível em: < http://ubes.org.br/2016/ubesdivulgalista-de-escolas-ocupadas-e-pautas-das-mobilizacoes/> Acesso em 08 dez. 2017.

${ }^{3}$ A Reforma do Ensino Médio apresenta alterações na estrutura do ensino, tendo seu currículo orientado pela Base Nacional Comum Curricular (BNCC), que vai se basear por itinerários formativos, orientado de acordo com as áreas de ensino. Dá "autonomia" aos sistemas de ensino para definir a organização das áreas de conhecimento a serem desenvolvidas em cada escola, assim como as suas competências e habilidades.
} 
Eles comportam tudo, desde o surgimento das respostas críticas em relação ao ambiente material ou menos carente em nossa primeira infância, do nosso primeiro encontro com a poesia e a arte, passando por nossas diversas experiências de trabalho, sujeitas a um escrutínio racional, feito por nós mesmos e pelas pessoas com quem as partilhamos e, claro, até o nosso envolvimento, de muitas diferentes maneiras e ao longo da vida, em conflitos e confrontos, inclusive as disputas morais, políticas e sociais dos nossos dias. Apenas uma pequena parte disso tudo está diretamente ligada à educação formal. (MÉSZÀROS, 2008, p.53)

A sua formação crítica está assim, atrelada as relações constitutivas da sua vivência, sendo somente a partir da vivencia com os outros que o indivíduo desenvolve suas próprias concepções, "vê-se então que os indivíduos se criam uns aos outros, no sentido físico e moral" (MARX; ENGELS; 1998; p. 35)

Sendo então, a partir das relações materiais que o indivíduo desenvolve suas concepções de mundo, estando necessariamente atrelada a organização social da vida material. E, na mesma medida, é a partir dos processos vivenciados que o indivíduo vai desenvolver condições para formação de um pensamento crítico.

A partir do processo de ensino, enquanto aspecto permanente na vida do indivíduo, que são desenvolvidas condições para superação das relações mercantilizadas incorporados ao espaço de ensino, levantando o papel (soberano) da educação na construção de novas relações sociais. Sendo somente através de uma percepção crítica ao processo ideológico presente nas diversas instâncias da vida do indivíduo que é possível a projeção de uma educação emancipatória.

Mas para tornar essa verdade algo óbvio, como deveria ser, temos de reivindicar uma educação plena para toda a vida, para que seja possível colocar em perspectiva a sua parte formal, a fim de instituir, uma reforma radical. Isso não pode ser feito sem desafiar as formas atualmente dominantes de internacionalização, fortemente consolidadas a favor do capital pelo próprio sistema educacional formal. (MÉSZÀROS, 2008, p.55)

Em um movimento de visualização das relações produtivas incorporadas ao processo educacional demonstra-se possível a sua superação. A partir do desenvolvimento de uma consciência crítica- condição prévia para o desencadeamento da ação coletiva, que é percebido o "sistema de internacionalização" no qual está inserido.

Ao internalizar as onipresentes pressões externas eles devem adotar as perspectivas globais da sociedade mercantilizada como inquestionáveis limites individuais a suas aspirações pessoais. Apenas a mais consciente das ações coletivas poderá livrá-los dessa grave e paralisante situação. (MÉSZÀROS, 2008, p. 45)

Visualizando o processo de consciência enquanto uma conceitualização que pretende explicar esse movimento de criticidade. Compreendo este enquanto um movimento que não é linear nem contínuo, tendendo a revisitar suas diferentes formas ao longo do seu desenvolvimento. Segundo Iasi "O processo de consciência é ao mesmo tempo particular, 
enquanto processo subjetivo de cada indivíduo e universal, quando falamos em consciência de classe" (IASI, 1999, p.14).

Estabelecendo o espaço escolar enquanto crucial na formação do indivíduo e protagonista em seu processo de concepção crítica. É, potencialmente, espaço de negação a valores internalizados a partir da sua primeira instituição de socialização: a família. $\mathrm{O}$ indivíduo encontra-se, em uma condição de superação da consciência individual (referente às relações estabelecidas na esfera privada), ao conceber-se enquanto parte de uma categoria.

Sendo esse momento formador de uma identidade coletiva e potencial para a mobilização estudantil. Segundo Iasi "Ao vislumbrar no outro a mesma condição que considera enquanto injusta é partilhada de uma identidade grupal, possibilitando a ação coletiva" (IASI, 1999, p. 34).

Durante as ocupações os estudantes organizaram espaços de ensino, somando a esse processo, estudantes da universidade, educadores e artistas. Na construção de um espaço e projeto de ensino propostos pelos estudantes, sendo já reforçado aquilo afirmado por Iasi "a educação formal e a não formal é essencial" (IASI, 2013, p.79), ao processo de formação e na construção da emancipação humana.

É desta forma, possível afirmar o espaço construído durante as ocupações no ano de 2016, enquanto um espaço primordial, tanto para a luta política dos estudantes e na construção histórica nacional dos movimentos sociais, quanto no sentido pedagógico, no qual os estudantes compreenderam seu papel crucial na construção de uma educação que se distancie de uma lógica neoliberal de ensino, assumindo o curso do seu processo de ensino durante aquele período.

A classe trabalhadora é ao mesmo tempo uma classe da ordem do capital, e por isso expressa na sua consciência os elementos do amoldamento e, exatamente por ser uma classe da ordem do capital, pode entrar em choque com esta ordem almejando ir além dela e, quando o faz, expressa uma consciência que pode chegar a uma consciência de classe. (IASI, 2013, p.74)

Segundo o autor italiano Antonio Gramsci, todo indivíduo exerce uma atividade intelectual e participa de uma concepção de mundo, contribuindo para manter ou modificar a ordem vigente. Sendo somente a partir da disputa consciente desses processos que teremos condições de rompimento com relações travadas a partir da estratificação social.

Em suma, todo homem, fora de sua própria profissão desenvolve uma atividade intelectual qualquer, ou seja, é um "filósofo", um artista, um homem de gosto, participa de uma concepção de mundo, possui uma linha consciente de conduta moral, contribui assim para manter ou para modificar uma concepção de mundo, isto é, promover novas maneiras de pensar. (GRAMSCI, 1982, p. 7-8) 
Afirmando a necessária disputa na educação, a partir de um enfrentamento ao amoldamento do Estado sob os processos de aprendizagem. E, compreendendo que esta disputa não ocorre de forma isolado ao sistema formal de ensino, mas justamente em sua construção cotidiana e abrangendo processos que ocorrem para além deste.

Demonstrando-se um instrumento essencial no curso dessa disputa, o reconhecimento dos processos de ensino que derivam das vivências do indivíduo e em espaços que não necessariamente são orientados segundo as perspectivas do capital, mas que pelo contrário, decorrem das ações de enfrentamento à sua lógica. Sendo estes, processos essenciais ao desenvolvimento de uma consciência crítica, orientando-se no sentido de formulação de um sistema educacional e societário verdadeiramente emancipatórios.

\section{Conclusão}

Nesse sentido, compreende-se que apenas através do reconhecimento de uma educação que está para além das relações formais e sancionadas pelo Estado que é possível um enfrentamento às ameaças direcionadas ao campo educacional.

Afirmando a inviabilidade de refletir sobre o papel da educação enquanto formadora de novas relações sociais nos limites da educação institucionalizada. Amparando como base para as reflexões no campo da educação, os diversos espaços e processos de aprendizagem sob os quais o indivíduo está inserido, propondo neste sentido, um debate para além das relações formais de ensino, mas que constituem diferentes âmbitos vida social.

Por compreender enquanto inviável refletir acerca destes processos de forma isolada, mas pensando-os em correspondência e com tarefa de intervir no sistema político-educacional em vigor. Buscando, nas ações coletivas relativas ao último período amparo para pensar o repertório de ação para o atual cenário.

Tendo enfoque sobre a luta dos secundaristas referente ao ano de 2016, por visualizar a potencialidade de formulação acerca de um projeto educacional emancipatório, pautado a partir de um formato de ensino que estava em dissonância com a lógica de estratificação social própria do atual do sistema produtivo e incorporada na mesma medida no sistema educacional.

Colocando para reflexão, afirmação já pontuada por Mészàros (2008) a educação tem uma tarefa soberana na construção de novas relações sociais. Exercendo papel essencial no processo de socialização dos indivíduos, ao compreender processos educativos que ocorrem em diferentes âmbitos de sua vivência e, são essenciais na constituição de uma prática de enfrentamento ao sucateamento da educação pública. 
Afirmando neste sentido, a mobilização política enquanto um espaço que educa e forma o indivíduo enquanto sujeito crítico, com possibilidades de intervenção no curso da construção no campo educacional e na sociedade em sua amplitude.

\section{Referências}

GALVÃO, Andéia. Marxismo e os Movimentos Sociais. Revista Crítica Marxista, Campinas n. 32, p. 107-126, 2011.

GRAMSCI, Antonio. Os Intelectuais e a Organização da Cultura. Rio de Janeiro: Editora Civilização Brasileira, 1982.

IASI, Mauro. Processo de Consciência. São Paulo: CPV, 1999.

IASI, Mauro. Educação e Consciência de Classe: Desafios Estratégicos. Perspectiva, Florianópolis, v. 31, n. 1, 67-83, jan / abr. 2013

MARX, Karl; ENGELS, Friedrich. A Ideologia Alemã. Tradução: Luis Claudio de Castro e Costa. 2. ed., São Paulo: Martins Fontes, 1998.

MÉSZÁROS, István. A educação para além do capital. $2^{\circ}$ ed. São Paulo: Boitempo, 2008. 